DOI 10.37882/2223-2982.2021.11.03

\title{
МЕТАФОРИЗАЦИЯ ПРИЛАГАТЕЛЬНЫХ ОБЪЕМНО-ПРОСТРАНСТВЕННОГО ЗНАЧЕНИЯ В АНГЛИЙСКОМ И РУССКОМ ЯЗЫКАХ
}

\section{METAPHORIZATION OF SPATIAL ADJECTIVES IN ENGLISH AND RUSSIAN}

\section{Achaeva}

Summary: The article is devoted to the description of adjectives with a volumetric-spatial and parametric meaning on the material of the English and Russian languages in the aspect of their metaphorization. Metaphorical transfer is considered as a means of conceptualizing new experience, and metaphor is one of the ways of cognizing the surrounding reality, it contributes to the emergence of new meanings, while performing a nominative and meaning-forming function. It was found that in the process of metaphorization, the lexemes under study often lose volumetric-spatial features and act as units characterizing a person's personality, characteristics of a person, his mental states, etc. Adjectives and their derivatives in English are characterized by a higher degree of metaphor, which does not always find adequate expression in the compared language.

Keywords: metaphorization of meaning, adjectives of volumetric-spatial meaning, derivative word, objective reality

\author{
Ачаева Марина Сергеевна \\ К.филол.н., дочент, Елабужский институт Казанского \\ федерального университета \\ marinachaeva@mail.ru
}

Аннотация: Статья посвящена описанию прилагательных с объемно-пространственным и параметрическим значением на материале английского и русского языков в аспекте их метафоризации. Метафорический перенос рассматривается как средство концептуализации нового опыта, а метафора представляет собой один из способов познания окружающей действительности, она способствует возникновению новых значений, выполняя при этом номинативную и смыслообразующую функцию. Установлено, что в процессе метафоризации, исследуемые лексемы часто утрачивают объемно-пространственные признаки и выступают как единицы, характеризующие личность, признаки человека, его психические или ментальные состояния и др. Прилагательные и их дериваты в английском языке характеризуются более высокой степенью метафоричности, которая не всегда не находит адекватного выражения в сопоставляемом языке.

Ключевые слова: метафоризация значения, прилагательные объемно-пространственного значения, производное слово, объективная действительность.
Л ексико-семантическая группа прилагательных объемно-пространственного значения (параметрических прилагательных или прилагательных размера) выступает в качестве универсального класса слов почти для всех языков. Во многом это обусловлено тем, что пространственные прилагательные подобного рода в полной мере отражают процесс познания человеком явлений объективной действительности, которые его окружают в процессе жизнедеятельности. Лексико-семантические варианты значений прилагательных традиционно входят в смысловые группы с семантикой расстояния, размера, пространства или времени. Стоит отметить, что в большинстве случаев такие прилагательные будут вступать в антонимические отношения и передавать различные элементы значения (например, характер расположения в пространстве чего-либо) [2, с.106].

Представления относительно параметрических признаков предметов и о пространстве, которые закодированы в том или ином языковом значении и вербализированы в словах, будут обнаруживать себя в рамках процесса семантической и словообразовательной деривации. Стоит отметить, что анализ признаковых слов, которые выступают в качестве объекта словоо- бразовательной детерминации, весьма ощутимо позволяет приблизиться к осознанию языковой картины мира в целом и осознанию языковой картины того или иного народа. Именно это позволит определять своеобразие мироощущения определенного народа, а также национально-культурную специфику языка, взаимосвязи языка с духовной и материальной жизнью народа.

Представляется, что пространство, будучи универсальной категорией бытия, традиционно занимает основную позицию в жизнедеятельности людей. Во многом это предопределено тем, что человек постоянно будет обращаться к пространству и будет выступать в качестве его участника или пассивного наблюдателя за всем, что происходит вокруг нас. Как следствие, вступив в пространственные отношения человек будет взаимодействовать с рядом абстрактных сущностей и рядом конкретных объектов. В качестве итогового результата данного взаимодействия можно назвать оценочную категоризацию, а также концептуализацию этих явлений и объектов на базе пространственных характеристик, которые ранее сложились в сознании и которые будут репрезентировать многогранный и сложный концепт SPACE [4, c.491]. 
По своей семантике все прилагательные не являются однородными, а их разнообразные классификации будут опираться на значения указанных прилагательных и на свойства денотатов, к которым можно отнести как признаки, так и интенсификации. Как правило, выделяют прилагательные, которые характеризуются как оценочные: хороший, плохой; параметрические прилагательные: широкий, узкий; прилагательные, обозначающие цвет: алый, бледный, рыжий, синий; прилагательные, отображающие пространственные и временные качества и отношения: прямой, правый, короткий; прилагательные, обозначающие свойства и качества вещей, воспринимаемые чувствами: пряный, кислый, жидкий, редкий; внешние или физические, телесные качества людей: босой, голый, нагой, хилый, полный; внутренние качества, черты характера, психологического склада: хороший, злой, хитрый, храбрый, жестокий и др. [6, с.151].

Семантическая структура прилагательных объемнопространственного значения, равно как и их функционально-прагматические свойства и когнитивные характеристики заслуженно вызывают исследовательский интерес ученых-лингвистов. Так, как справедливо отмечается в литературе, они в полной мере отражают процессы вербализации ментальных (а также когнитивных и концептуальных) параметрических представлений человека относительно размера в языке. Данные лексемы, выступая в качестве репрезентантами пространства, могут быть отнесены к классу достаточно активно используемых номинаций. Как следствие, все слова, которые будут относиться к группе параметрических прилагательных, либо прилагательных объемно-пространственного значения, должны расцениваться в качестве многозначных лексем. Стоит отметить, что по отношению друг к другу значения многозначных слов могут различаться как номинативно-непроизводные (основное, исходное значение) и номинативно-производные, а также как метафорические (всегда производные) значения.

В представленной статье содержится анализ прилагательных с семантикой объема, параметра или пространства на базе английского и на базе русского языке в аспекте их метафорической номинации. Отметим, что нынешний этап развития и существования лингвистической семантики находиться под пристальным вниманием ученых, которые пытаются понять природу и характер метафорических переносов, а также рассмотреть их через призму средства для концептуализации нового опыта. Стоит отметить, что именно метафора будет пронизывать всю нашу жизнь и находить свое проявление в языке, а также в действии и мышлении.

Также в рамках настоящего исследования стоит подчеркнуть тот факт, что деятельностный аспект метафоры тесно взаимосвязан с так называемым «человеческим фактором в языке». Так, именно благодаря ему в языко- вом средстве удается запечатлеть национальное и культурное богатство, накапливаемое языковым коллективом в рамках его исторического развития [8, с.98].

Метафора всегда является одним из способов познания человеком объективной действительности, в том числе, объектов, которые выступают в качестве ее структурных элементов. Стоит отметить, что метафора в данном аспекте будет выполнять функцию наименования указанных объектов, а также позволит создавать художественные образы, формировать новые знания. Отсюда следует, что метафора будет выполнять художественную, когнитивную, номинативную и смыслообразующую функцию.

Стоит отметить, что узкое (ограниченное) понятие метафоры тесно взаимосвязано с тем, что ее выделяют в качестве самостоятельного тропа, что в полной мере исключает ее отнесение к числу метафор, к которым обычно причисляются образные средства (например, сравнения и иные). В этом аспекте интерес представляет точка зрения И.М. Некипеловой, которая понимала под метафорой процесс замещения компонентов в смысловой структуре свойства, что свойственно первоначальному понятию и компонентам, определяющим включение слова в определенную лексико-семантическую группу или класс [5, с.15]. Действительно, трудность характеристики метафоры состоит в том, что в ее основе заложены достаточно сложные психологические ассоциации, которые едва ли можно оценить как простое сходство значений по отдельным компонентам. Это обусловлено тем, что в логических моделях метафор, ассоциативный образ находится между двумя словесными компонентами.

Представляется, что в основу метафоры заложены различные как физические, так и социальные явления. Согласованность в рамках общей системы отчасти объяснят выбор того или иного явления. Иллюстрацией данного примера может служить то, что состояние счастья в физической среде, как правило, взаимосвязано с улыбкой и общим состоянием открытости, что может служить основанием метафоры: Happy is wide; sad is narrow 'C4aстье - широкое; грусть - узкое'. Одновременно с этим, в языке основой для выражения данного состояния будет выступать ассоциация счастья с верхом. В частности, принято говорить о вершине счастья, а не о ширине счастья. Метафора счастье - верх максимально согласована с метафорами хорошее - верх, здоровье - верх и т.п.

Прилагательные объемно-пространственного значения также всегда характеризуются достаточно высокой степенью метафоризации своих значений, что порождает ослабление или утрату семантики параметрических значений.

Среди английских значений прилагательных, кото- 
рые изучаются в данном исследовании, стоит выделить лексические единицы с фразеологизированным типом семантики: wide fellow - ловкач, wide females - непотребные женщины; the narrow house - тесное жилище (о могиле). В обоих языках существующие различия в культурной значимости понятий пространственного плана отражаются в корпусе устойчивых словосочетаний с указанными словами. Например, устойчивое словосочетание товары широкого потребления достаточно привычно для русского языкового сознания, о чем явно свидетельствует его английский перевод: consumers' goods (букв.: потребительские товары).

Что касается параметрических прилагательных, то они выступают в качестве единиц измерения личности. В частности, они могут описывать человека в целом, а также отдельные качества его личности, свойства и характеристики. Например: широкий специалист, широкий кругозор; прилагательное широкий в данном случае означает то, что кто-то или что-то лишено ограниченности, определенной узости: широкий взгляд на вещи, в широком смысле слова; широкий соизмеряется с проявлением чувств: широкая душа, широкая натура. Стоит отметить, что в английском языке некоторые прилагательные будут обладать похожей семантикой: a man of vast soul - человек большой души; vast interests - широкий круг интересов (букв. vast - обширный, огромный); данные значения могут наследоваться и производными прилагательных размера: a width of mind - широта взглядов [3, с.187].

Некоторые значения прилагательных, используемых в русском языке, будут образовывать словосочетания, семантика которых является достаточно идиоматичной. Аналогичные единицы в английском языке не имеют лексико-структурных соответствий и могут передаваться путем иных лексических единиц, например: широким фронтом (повсеместно, с большим охватом) - on a large scale; жить на широкую ногу - live in (grand) style, live in opulence; широкой рукой (щедро, с размахом) - lavishly и др.; узкое место (наиболее уязвимая и слабая сторона в деле, создающая определенные трудности, затруднения) - bottleneck; weak point: узкое место в производстве - a weak point in manufacture; встретиться (или столкнуться) на узкой дороге (дорожке) - (столкновение противоположных, в том числе, враждующих сторон, интересов) - collision of hostile interests [1, с.143].

Представляется, что в русском языке такая лексема, как узкий может использоваться в переносном смысле и характеризовать профессиональные характеристики человека, например: узкий специалист. Кроме того, с ее помощью можно охарактеризовать и недалекого человека, например: человек с узким кругозором. В свою очередь, в английском языке такие прилагательные имеют похожую семантику: narrow mind - духовная ограни- ченность, узколобие; narrow opinions - узость взглядов; narrow understanding - ограниченное понимание. Стоит отметить, что существующие различия в культурной значимости таких пространственных понятий находит свое отражение в рамках устойчивых словосочетаний с такими словами в обоих языках. На практике носители обоих языков будут прибегать к различным способам объективизации явлений окружающей действительности. Так, в английском языке прилагательное narrow в рамках характеристики человека означает: 'скаредный; прижимистый': to be narrow with one's money - не любит расставаться с деньгами, скаредничать.

Также стоит рассмотреть английские номинативные единицы, которые не имеют аналогов в русском языке в силу метафоричности своего значения. Например, narrow circumstances - стесненные обстоятельства; narrow majority - незначительный перевес голосов, незначительное большинство; narrow means - ограниченные средства (букв.: узкие); narrow choice - ограниченный выбор; to have a narrow escape - спаситись, избежать гибели (букв. чудом избежать гибели; narrow victory - одержать победу с незначительным, небольшим преимуществом (узкая победа) [7, с.184].

В ряде случаев в английских наречиях семантика параметрического признака будет изменяться и передаваться на русский язык при помощи других основ, которые также можно отнести к системе пространственного восприятия: to be widely mistaken - глубоко заблуждаться, widely separated - далеко отстоящие друг от друга. Модификационным типом значения также будут обладать производные прилагательные, например: widish (широковатый, достаточно широкий), narrowish (узковатый), longish (длинноватый) и др. Суффикс -ish в данном случае будет означать ослабление определенного признака или качества, которое обозначается основой прилагательного.

Также в этом аспекте стоит акцентировать внимание на том, что broad выступает в качестве «вершины» самостоятельного лексического и словообразовательного гнезда в рамках английского языка, а его семантическая структура будет иметь весьма яркие особенности. Так, отадъективное наречие broadly (широко) часто употребляется в метафорическом значении: broadly speaking вообще говоря, в общих чертах; he looked at me broadly in the face - он прямо посмотрел мне в лицо (букв.: посмотрел широко в лицо); broadly - с акцентом, ср. broad Scotch accent - сильный шотландский акцент. Кроме того, в английском языке присутствует достаточно большое количество производных с так называемой «национально-культурной» семантикой: broad-arrow - английское правительственное клеймо; broad-piece - старинная золотая монета в двадцать шиллингов; broad seal - большая государственная печать; broadwife - (амер. ист.) 
жена раба, которая принадлежит иному хозяину. Стоит отметить, что первоначальное прилагательное в этом случае нередко имеет и переносные значения, например: in a broad sense it is true - в широком смысле это верно, in broad daylight - средь бела дня и иные.

Как в английском, так и в русском языке прилагательные, которые относятся к прилагательным объемнопространственного назначения, будут демонстрировать способность образовать сложнопроизводные прилагательные, которые имеют разнообразную логическую структуру. Некоторые такие производные активно применяются в целях описания физических характеристик человека. Например: узкоглазый - narrow-eyed, узкогрудый - narrow-chested. В английском языке производные такой смысловой общности также могут иметь вид единиц, которые будут характеризоваться фразеологизированным типом семантики: narrow-souled - мелкий, пустой (о человеке): narrow-souled person - мелкая душонка; narrow-spirited - ограниченный, с узкими взглядами. Стоит отметить, что некоторые из них выступают в качестве основы для описания иных деривационных процессов: narrow-minded man (узкий, недалекий человек) - narrowmindedness (узость взглядов). Однако лишь некоторые английские дериваты будут иметь аналоги в русском языке, например: narrow-sighted - (редк.) близорукий (букв.: с узким зрением); long-sighted - дальнозоркий, дальновидный (букв.: с длинным зрением), long-sightedness -дальновидность или дальнозоркость.

Анализируемые слова в рамках русского языка будут производить префиксальные, суффиксальные и префиксально-постфиксальные глаголы со словообразовательным значением 'наделять кого - что-либо тем признаком, который назван мотивирующим прилагательным'. Например, известно, что в русском языке у производных глаголов подкоротить, укоротить, сократить, подсократить, окоротить в качестве основного компонента значения будет выступать 'сделать что-либо более коротким' с позиции времени и пространства. Одновременно с этим, в английском языке указанная глагольная семантика будет выражаться только производным to shorten: to shorten working time - сократить рабочий день. Одновременно с этим, в отличие от русских суффиксально-префиксальных глаголов, производный глагол в английском языке обладает метафорическим значением: to shorten the arm of somebody - ограничить власть. Дериват to widen (расширять, расширяться) будет номинировать параметрический признак, а степень метафоричности в данном случае (равно как и степень идиоматичности) семантики будет наиболее ярко выражена у глагола to broaden: to broaden one's outlook - расширить свой кругозор; his conceptions were broadened - он стал шире смотреть на вещи; her face brightened and broadened out into a beaming smile - ее лицо просияло и появилась широкая улыбка. Также стоит акцентировать внимание на том, что глагольные лексемы в английском языке зачастую подтверждают наличие особого способа, который применяется для концептуализации пространственных отношений: to narrow one's lids - прищуриться (букв.: сузить веки); to narrow the enemy - теснить противника; to narrow down the dispute - свести спор к нескольким (существенным) вопросам (букв.: сузить). Отсюда следует, что в семантике указанных единиц можно наблюдать метафорический перенос свойств физических параметров на отвлеченные параметры.

Традиционно в английском языке глаголы будут характеризоваться национально-специфическими компонентами значения: to long (for, after) - страстно желать, стремиться: to long to go away - стремиться уйти; I longed for a drink - я ужасно хотел пить, в моем горле все пересохло. Отметим, что указанный компонент значения также наследуется производными словами: longing - сильное желание, страстное стремление: a longing for home - тоска по дому; longing eyes -тоскующие глаза; longingly - с тоской, жадно, нетерпеливо. Национально-культурной семантикой будет обладать русская лексема коротать 'заполнять, занимать чем-либо время для того, чтобы оно прошло как можно скорее (незаметно)': коротать вечер, коротать время, жизнь, дни. Очевидно, что понятие времени будет приобретать в данном случае так называемую «национально-культурную окраску». В свою очередь, лексема с корневой морфемой short в английском языке сегодня не предусмотрена. В данном аспекте стоит отметить, что такие лексемы будут образовывать область лексической и словообразовательной лакунарности, которая явно свидетельствует о имеющемся национальном своеобразии семантической структуры английского и русского языка.

Можно констатировать, что исследование особенностей семантической структуры прилагательных объемно-пространственного значения, а также их дериватов позволило обнаружить определенные особенности репрезентации пространственных отношений в английской и русской лингвистической культуре. Установлено, что прилагательные объемнопространственного значения в рамках речевой деятельности достаточно активно подвержены метафоризации. В связи с этим, в своем переносном значении они вполне могут пересекаться с прилагательными из иных лексико-грамматических групп. Кроме того, можно сделать вывод о том, что в рамках метафоризации анализируемые лексические единицы в английском и русском языке часто утрачивают свои объемно-пространственные признаки и вполне могут характеризовать внешние признаки человека, его личность, свойства его характера, а также ментальные и психологические состояния. Кроме того, прилагательные, а также их дериваты в английском языке обладают весьма высокой степенью метафоричности, что не всегда 
находит свое адекватное отражение в русском языке, так как формулировки подобного рода в русском языке могут попросту отсутствовать. Кроме того, в статье было установлено, что прилагательные подобного рода обладают достаточно сложной и весьма неодно- значной семантикой, а их дериваты могут актуализировать различную комбинацию смыслов. В связи с этим, указанная тема представляет собой определенный исследовательский интерес и может стать предметом дальнейших научных изысканий.

\section{ЛИТЕРАТУРА}

1. Кубрякова Е.С. Роль словообразования в формировании языковой культуры мира / Е.С. Кубрякова // Роль человеческого фактора в языке: язык и картина мира. - М.: Наука, 1988. - С.141-172.

2. Кубрякова Е.С. Типы языковых значений: Семантика производного слова / Е.С. Кубрякова. - M.: URSS, 2008. - 198с.

3. Лакофф Дж. Метафоры, которыми мы живем / Дж. Лакофф, М. Джонсон. - М.: Едиториал УРСС, 2004. - $256 \mathrm{c}$.

4. Мякшин К.А. Явление метафоризации в терминологии / К. А. Мякшин // Молодой ученый, 2013. - № 7 (54). - С. 490-494.

5. Некипелова И.М. Метонимическая и метафорическая деривация в истории русского языка (на материале памятников деловой письменности XI-XVII веков): автореф....дис. ...канд. филол. наук / И.М. Некипелова. - Казань, 2005. - 28с.

6. Ташлыкова М.Б. Параметрические прилагательные как единицы измерения масштаба личности / М.Б. Ташлыкова // Русский язык: исторические судьбы и современность: III межд. конгресс исследователей рус. яз. М.: МАКС Пресс, 2007. - С.151-152.

7. Черемисин А.Н. Прилагательные пространственной семантики как средство репрезентации оценки в современном английском языке: дис. . . канд. филол. наук / А.Н. Черемсин. - Тамбов, 2015. - 199с.

8. Шрамм А.Н. Очерки по семантике качественных прилагательных: на материале современного русского языка / А.Н. Шрамм. - Л.: Изд-во Ленинград. ун-та, 1979. - 134с.

(с) Ачаева Марина Сергеевна (marinachaeva@mail.ru).

Журнал «Современная наука: актуальные проблемы теории и практики»

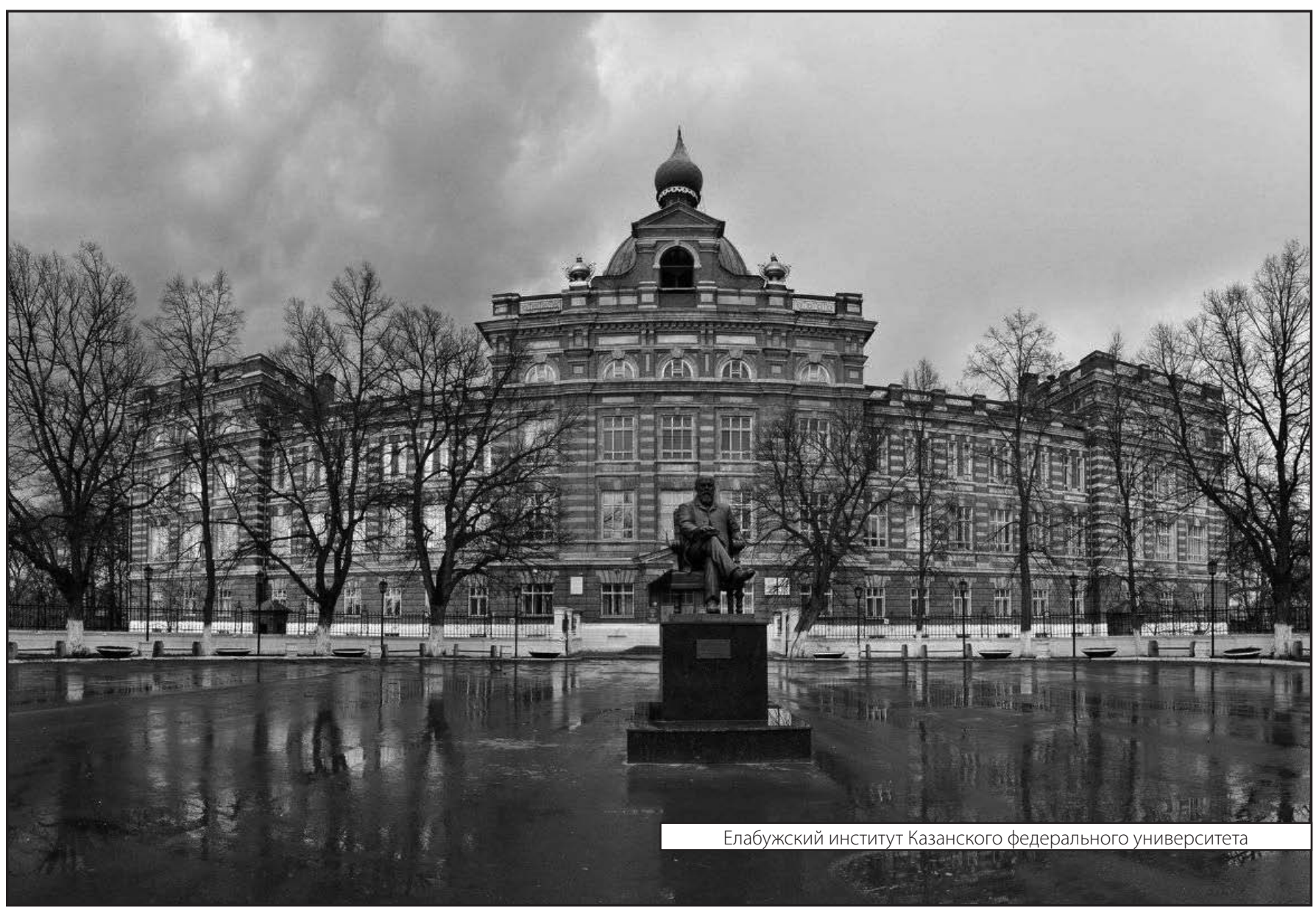

